\title{
Miranda
}

Revue pluridisciplinaire du monde anglophone /

Multidisciplinary peer-reviewed journal on the English-

speaking world

19 | 2019

Rethinking Laughter in Contemporary Anglophone Theatre

\section{Regard sur Holy de la compagnie Affari Esteri}

Festival Le Temps d'Aimer la Danse, Biarritz, Le Colisée, 7 septembre 2019

\section{Nathalie Vincent-Arnaud}

\section{CpenEdition}

\section{Journals}

Édition électronique

URL : http://journals.openedition.org/miranda/20620

DOI : $10.4000 /$ miranda.20620

ISSN : 2108-6559

\section{Éditeur}

Université Toulouse - Jean Jaurès

Édition imprimée

Date de publication : 7 octobre 2019

\section{Référence électronique}

Nathalie Vincent-Arnaud, « Regard sur Holy de la compagnie Affari Esteri », Miranda [En ligne], 19|

2019, mis en ligne le 09 octobre 2019, consulté le 16 février 2021. URL : http://

journals.openedition.org/miranda/20620 ; DOI : https://doi.org/10.4000/miranda.20620

Ce document a été généré automatiquement le 16 février 2021.

\section{(c) (i) (3)}

Miranda is licensed under a Creative Commons Attribution-NonCommercial-NoDerivatives 4.0 International License. 


\title{
Regard sur Holy de la compagnie Affari Esteri
}

\author{
Festival Le Temps d'Aimer la Danse, Biarritz, Le Colisée, 7 septembre \\ 2019
}

Nathalie Vincent-Arnaud

1 http://letempsdaimer.com/compagnie/affari-esteri/

2 Le lieu est retiré, presque confidentiel, comme surgi au hasard d'une rue à l'écart des scènes centrales emblématiques du Temps d'Aimer la Danse (Gare du Midi, Casino) et de la rumeur de l'océan en cette fin d'après-midi de septembre à l'approche des grandes marées d'équinoxe. Le fond de scène bétonné noir quasi brut de décoffrage de ce petit théâtre en gradins de quelque 200 places s'assortit pour la circonstance d'un décor dépouillé. Comme en écho à ce minimalisme, le danseur Shlomi Tuizer, exmembre de la Batsheva Dance Company et fondateur avec Edmond Russo de la compagnie Affari Esteri en 2005, est seul en scène, devant relever l'immense défi que représente l'incarnation, en moins d'une heure, du poème-cri de Ginsberg, «Howl », dont le souffle, la charge symbolique et émotionnelle, le caractère de manifeste transgénérationnel ne peuvent se mesurer qu'à ceux d'autres monuments poétiques tels que «The Wasteland» de T.S. Eliot.

3 L'adaptation chorégraphique de « Howl " peut sembler relever de la gageure en raison, précisément, du caractère monumental de l'œuvre et de la myriade d'images qui s'y télescopent en lançant de très nombreux défis à l'interprétation. Néanmoins, en soi, le devenir-danse du poème est évident en raison de la structure même de celui-ci, de sa charpente heurtée et convulsive. Les multiples élans et emballements du texte, ses rebonds et ses résurgences composent une matière hautement corporalisée soustendue par le phrasé obstiné de la voix poétique.

4 À cette voix "ensauvagée ", ${ }^{1}$ qui ne connaît aucune trêve dans son acharnement et l'éternel retour du même, répond un corps ensauvagé qui, au tout début de la pièce, se perd en errances et en tâtonnements à même un sol dont il ne s'affranchit qu'au bout de quelques instants, ne gagnant tout d'abord la verticalité que pour retourner à sa position initiale. En contrepoint de cette longue séquence résonnent en voix off les 
premiers vers du poème, dont le déroulement linéaire est respecté d'un bout à l'autre de la performance. Du murmure initial au cri, les voix qui se succèdent, masculines et féminines, en français et en anglais, parcourent toute une gamme d'intensités et de débits, composant avec les jeux de lumière - de la pénombre aux pleins feux en passant par les éclairs stroboscopiques -, tandis qu'aux paroles emblématiques de « Losing My Religion » de R.E.M., égrenées dans l'accalmie d'un a cappella en fondu-enchaîné aux voix du poème, fait place le déchaînement d'une bande-son rock et post-punk (The Fall, The Pixies). Les traversées de scène dans des costumes divers endossés à la hâte chapeau, street wear, tee-shirt de hipster, gants noirs et autres éléments de travestissement - s'enchaînent, déambulations, courses et sauts en alternance, comme autant de déclinaisons d'identités successives sur la trame continue des voix et des musiques qui déferlent. Ces variations - tempi et costumes, ces derniers finissant par joncher le sol dans une démarche d'allègement progressif - se trouvent prolongées par l'extrême plasticité d'un corps tour à tour traqué et conquérant dont la grammaire semble poursuivre son exploration à l'infini entre girations, pirouettes, isolations multiples qui n'ont de cesse de déporter corps et regard vers d'autres lieux, d'autres modes d'être, d'autres horizons.

5 L'avant de la scène est occupé par trois livres disposés à intervalles réguliers, ouverts successivement au cours de la pièce, dont on comprend au fur et à mesure qu'il s'agit du texte original du poème ainsi que de ses traductions en français et en hébreu. Le danseur s'immobilise à trois reprises pour devenir lecteur, sa voix prenant alors le relais des voix off accompagnant son évolution sur la scène. Chaque livre reposé, c'est le corps et la danse qui reprennent leurs droits pour exalter toute l'intensité incantatoire délivrée par chaque temps du texte. Textes français, anglais et hébreu sont ainsi distribués comme autant de jalons venant ponctuer les lectures par les voix off et servir de tremplin à de nouveaux élans de l'interprète à travers l'espace scénique.

6 C'est le texte hébreu, celui de la langue sacrée, qui fournit de manière éloquente le point d'orgue d'une performance dont la dernière étape donne corps à l'hymne final, «Holy! », apostille du poème qui donne son titre à l'ensemble. À travers des girations qui marquent un engagement de différentes parties du corps, puis du corps tout entier dans des formes sphériques apaisées, se déploie tout le kaléidoscope d'une appropriation graduelle et mesurée de l'espace sur un mode évoquant la kinésphère chère à Laban. La lenteur dans laquelle s'inscrivent globalement le mouvement et les ondulations du corps donnent à voir autant de parcelles de ce corps "sacré » dans sa prise de possession de l'univers alentour. Libéré de la pesanteur et des entraves de la séquence initiale, recomposant une unité battue en brèche par les lignes brisées, les sauts et les saillances erratiques du "Moloch", le corps semble s'abandonner aux volutes d'une quête et d'un désir infinis.

7 Tel un kaddish pour un ange tombé, le poème ré-affirme, au fil de retours et de soubresauts pleinement incarnés par la chorégraphie et la mise en scène, sa nature de partition d'une solitude et d'un désarroi en recherche d'essor salvateur. En cinquante minutes d'une extrême densité sont livrées aux sens du spectateur, outre la moire/ mémoire d'un texte fondateur, la richesse et la complexité d'une création chorégraphique contemporaine oscillant entre danse et théâtre, cri et murmure, figures du corps entravé et du corps libéré qui invitent, dans la simplicité qui lui sert d'écrin, à un authentique partage de questions, d'émotions, d'illuminations. 


\section{NOTES}

1. Référence à la définition que Michel Leiris, dans son ouvrage À cor et à cri, donne du cri comme étant un "ensauvagement de la voix" (Leiris 1988, 23).

INDEX

Mots-clés : adaptation, cri, danse, festival, performance, poème, voix

Keywords : adaptation, cry, dance, festival, performance, poem, voice

Thèmes : Music, Dance

\section{AUTEURS}

\section{NATHALIE VINCENT-ARNAUD}

Professeur

Université Toulouse Jean-Jaurès

nathalie.vincent-arnaud@univ-tlse2.fr 